Review

\title{
Managing Local Coastal Stressors to Reduce the Ecological Effects of Ocean Acidification and Warming
}

\section{Giulia Ghedini, Bayden D. Russell and Sean D. Connell *}

Southern Seas Ecology Laboratories DX 650 418, School of Earth and Environmental Sciences, University of Adelaide, South Australia 5005, Australia;

E-Mails: giulia.ghedini@adelaide.edu.au (G.G.); bayden.russell@adelaide.edu.au (B.D.R.)

* Author to whom correspondence should be addressed; E-Mail: sean.connell@adelaide.edu.au; Tel.: +61-8313-6125; Fax: +61-8313-4364.

Received: 5 August 2013; in revised form: 11 September 2013 / Accepted: 29 September 2013 / Published: 10 October 2013

\begin{abstract}
Anthropogenic activities have increased the number of stressors acting on ecosystems. When multiple stressors act simultaneously, there is a greater probability of additive, synergistic and antagonistic effects occurring among them. Where additive and synergistic effects occur, managers may yield disproportionately large benefits where they first act upon synergies. Stressors act, however, at different spatial and temporal scales. Global stressors (e.g., ocean acidification and warming) tend to change slowly over long periods of time, although their intensity and effects are contingent on local conditions. On the other hand, local stressors tend to change rapidly over shorter, more defined spatial and temporal scales. Hence, local stressors can be subject to a greater degree of control through local management (e.g., eutrophication and overfishing) while global stressors are characterized by an intrinsic inertia whose effects last for decades, if not centuries. Although the reduction of carbon emissions is an international priority for managing global stressors, it requires international agreements and management applications that take considerable time to develop. Managers, however, may 'buy time' by acting on stressors whose governance is local (e.g., reducing nutrient input) and are known to synergize with global stressors (e.g., enriched $\mathrm{CO}_{2}$ ). Such local actions may potentially disrupt synergies with the more slowly changing global stressors that can only be reduced over longer time scales.
\end{abstract}

Keywords: global stressors; local stressors; ocean acidification; nutrients; ocean warming; synergies; management 


\section{Introduction-Synergistic Effects between Long-Slow Global Stressors and Short-Rapid Local Stressors}

Since the Industrial Revolution, anthropogenic impacts over natural systems have constantly intensified, increasing the number of stressors acting simultaneously on terrestrial and marine systems. Although most stressors have an anthropogenic origin and occur worldwide, they present different characteristics on which they may be managed.

Increasing atmospheric $\left[\mathrm{CO}_{2}\right]$ from human activities drives environmental change at global scales (i.e., global and ocean warming, ocean acidification), which is related to a number of other climatic and non-climatic effects (e.g., ice melting, sea level rise, changes in upwelling and currents, storm pattern and intensity) [1,2]. $\mathrm{CO}_{2}$-related stressors originate at global scales primarily through the net effect of $\mathrm{CO}_{2}$ emissions. Although $\mathrm{CO}_{2}$ and associated stressors (e.g., temperature) act and exert their effects at global spatial scales, their manifestation is variable from global through to local scales [3]. For example, regional differences in their intensity and effects are dependent on local conditions [4]. The recognition of such differential manifestation of individual stressors is fundamental when considering the scale at which they can be managed or mitigated.

Broad-scale stressors tend to be drivers of change over long periods of time. Climate change stressors, indeed, act on ecosystems through gradual changes in terms of human history, although rates of change are unprecedented in their pace over geological time scales [5,6]. Such global climate stressors have an intrinsic inertia, meaning that their effects will persist and keep acting for several decades to centuries, even if action to radically reduce carbon emissions is taken now. For example, ocean absorption of atmospheric $\mathrm{CO}_{2}$ has decreased ocean $\mathrm{pH}$ by 0.1 units over the past 200 years, corresponding to about a $30 \%$ increase in the concentration of hydrogen ions [7]. Future decrease in $\mathrm{pH}$ mainly depends on the actions that will be undertaken to reduce $\mathrm{CO}_{2}$ emissions. If atmospheric $\left[\mathrm{CO}_{2}\right]$ continues to increase at the present rate, projections show that $\mathrm{pH}$ is likely to decrease a further 0.5 units by the year 2100 in surface oceans, with a three-fold increase in the concentration of hydrogen ions from pre-industrial times [8]. Changes in ocean $\mathrm{pH}$ of this magnitude and at this rate are well outside the range of natural variability and, even at the present level of ocean acidification, it would take thousands of years for ocean chemistry to return to the pre-industrial conditions $[8,9]$. Similarly, mean surface temperature has increased $\sim 0.7{ }^{\circ} \mathrm{C}$ over the past 100 years and is expected to raise a further $2-4{ }^{\circ} \mathrm{C}$ by the year 2100 , depending on the rate of increase of atmospheric $\left[\mathrm{CO}_{2}\right][6]$.

In combination with these global stressors, are rapidly changing stressors that originate and act at local scales, such as eutrophication, overfishing, habitat destruction and spread of non-native species [10-13]. Although such stressors are repeated across the globe, such that their combined impact can be measured at a global scale, they can be defined as "local" because their origin and effect can be identified and managed more easily at local through to regional scales than those of global change stressors. Moreover, local management can effectively reduce those stressors in a relatively short period of time, as they have relatively less inertia compared to global climate stressors. The effectiveness of the intervention could be key to avoid species loss and extinction.

Stressors can have interactive effects on populations and ecosystems when acting simultaneously. Interactive effects can be synergistic (i.e., multiplicative, non-additive) or antagonistic (i.e., opposite). Identifying whether synergies exist among stressors and which type of synergies they have, it is the 
first important step in ecological studies as a starting point to understand the effects of stressors and, then, the most effective way to manage them [14]. The probability of synergistic effects among global and local stressors increases when a larger number of stressors act simultaneously on natural systems, resulting in larger negative effects than the individual effects of single stressors [15-17]. Theoretically, therefore, the most powerful acts of management are those that manage the largest synergies first. There are a few well established synergies among global and local stressors. Ocean warming is one of the key stressors that has large synergistic effects with both local (i.e., nutrients) and global stressors (i.e., ocean acidification), ranging from species to ecosystem effects [18,19]. Global warming is a relatively slow changing stressor that is driven by atmospheric $\mathrm{CO}_{2}$ concentration. Thus, control of global warming can only be achieved through a reduction of $\mathrm{CO}_{2}$ emissions. Whilst a reduction of emissions is an international priority [1], meaningful reductions are unlikely in the short-term. Even if profound reductions of $\mathrm{CO}_{2}$ emissions can be adopted with the aim to decrease the rate of global warming and ocean acidification, it will take decades to stop these phenomena and to return to previous environmental conditions [1,8,20]. Given the intrinsic inertia of global climate change stressors and difficulty in reaching international agreements, it is fundamental to invest more in the possibility of reducing rapidly changing local stressors through management at local to regional scales.

Reduction of local stressors may 'buy time' to maintain the resilience of marine systems. Local stressors can be effectively managed at small spatial scales and environmental conditions can be improved over relatively short periods of time. Importantly, reduction of local stressors has already been shown to be effective at reducing synergies with global stressors. For example, reduction of nitrogen input in to oceans via terrestrial runoff can raise the upper thermal bleaching limit of corals, thus increasing their resilience to thermal stress and ocean warming [21].

\section{An Example from Kelp Forests}

When multiple stressors act simultaneously, there is a greater chance of synergistic effects. Some stressors, such as enriched $\mathrm{CO}_{2}$ and nutrients, act as resources among competitors for ecosystem dominance [22-24]. Change in resource availability alters the relative dominance of species such that subordinates can become dominant players and ecosystems can shift from one stable state to another. There are many examples of such ecological shifts in marine systems; most notably transitions from coral-dominated to macroalgal-dominated reefs [25], kelp-forests to mat-forming algae [26] and seagrass to sand [27].

Kelp forests represent a good example of a system that can shift from a diverse and productive system to one of lower species diversity and productivity. Kelps naturally dominate temperate subtidal rocky reefs, creating dense canopies over a substratum colonized by encrusting coralline algae [28,29]. Within kelp forests, gaps in the canopy are frequently created through natural events (e.g., extreme warming events, storms, grazing by sea urchins, diseases) [30-33]. Within newly created gaps mat-forming algae rapidly colonize the available substratum [34,35]. The expansion of mat-forming algae is usually limited by the shading and whip-lashing effects of the surrounding canopy and patches are gradually recolonized by kelp recruits [36]. This resilience, or ability for kelps to recover from disturbance, represents a normal dynamic of kelp forest ecology. 
When environmental conditions are altered by human activities (e.g., increased sedimentation, eutrophication) mat-forming algae are favored over kelp recruits [26]. Mat-forming algae have a sediment-trapping morphology and are fast growing species that are able to rapidly colonize substratum under elevated nutrient and sediment loading [37]. In contrast, kelp often fail to recruit under such conditions [34]. These processes (i.e., expansion of mat-forming algae and recruitment failure of kelp) gradually lead to a shift from kelp-dominated to turf-dominated reefs [38]. Resilience, therefore, is reduced by local activities (e.g., storm-water and sewage discharge, dredging) that alter the abiotic environment from scales of $100 \mathrm{~s}$ of meters to kilometers.

The subordination of kelp to turfs by local stressors is likely to be accelerated by global stressors. Turfs are opportunistic species that often benefit from the increasing availability of dissolved carbon dioxide in conditions simulating ocean acidification [39]; this is likely due to an increase in the use of diffusive $\mathrm{CO}_{2}$, which benefits species with limited or no ability to use $\mathrm{HCO}^{3-}$ [40]. Moreover, the combination of ocean warming and increased $\mathrm{CO}_{2}$ availability combine to facilitate the growth of mat-forming algae in a synergistic way [19]. When one or more global and local stressors combine, they facilitate the rate of expansion of turfs more quickly than the additive value of their individual effects [41]. This synergistic effect (i.e., a multiplicative rate) of expansion was unanticipated, but appears to be an example of phenomena that policy development may effectively manage.

Kelp forest systems that are disproportionately more sensitive to bottom-up factors, such as those found in South Australia, can benefit from reduction of local stressors, such as nutrient enrichment and sediment runoff. Preliminary evidence shows that improved water quality has the potential to substantially reduce the effects of global stressors on mat-forming algae, thus preventing further kelp loss [42]. By improving water quality, the synergistic links with global stressors are broken such that the effects are reduced by orders of magnitude. Kelp systems in other regions of the world (e.g., Eastern Australia, Gulf of Maine, North Norway) are, however, often top-down driven, with herbivores (i.e., sea urchins) playing a critical role in determining the abundance and biomass of primary producers [33]. Hence, these trophically-structured systems may benefit less from improved water quality. Despite this, local management still plays a fundamental role in maintaining the resilience of kelp forest and reducing the negative effects of climate change (Figure 1). These benefits can be obtained by maintaining trophic cascades and ensuring the presence of top predators (e.g., fish, lobsters) and competitors (e.g., abalone) which control the abundance of sea urchins (i.e., regulating fishing activities, establishing marine protected areas-MPAs) $[43,44]$. Having said that, the protection of trophic cascades and management of fishing activities would probably not benefit the persistence of kelp forests, if not coupled with interventions to improve water quality (i.e., nutrient enrichment, sediment runoff, pollution) [45].

By targeting local stressors that are known to elicit multiplicative effects with climate stressors, managers may yield disproportionately large results for their effort. In this regard, kelp systems provide an opportunity to investigate how the reduction of local stressors can disrupt synergies with global stressors that are not directly under the governance of local managers. 
Figure 1. Schematic representation of how local management could act to reduce local stressors, potentially disrupting synergies with global stressors.

BOITOM-UP DRIVEN

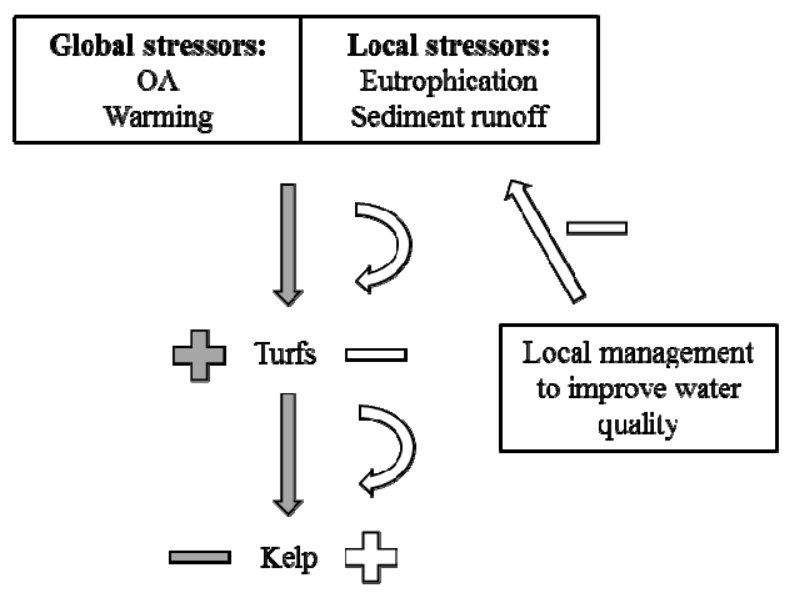

TOP-DOWN DRIVEN

\begin{tabular}{|c|c|}
\hline Global stressors: & Local stressors: \\
OA & Overfishing \\
Warming & Habitat fragmentation \\
\hline
\end{tabular}

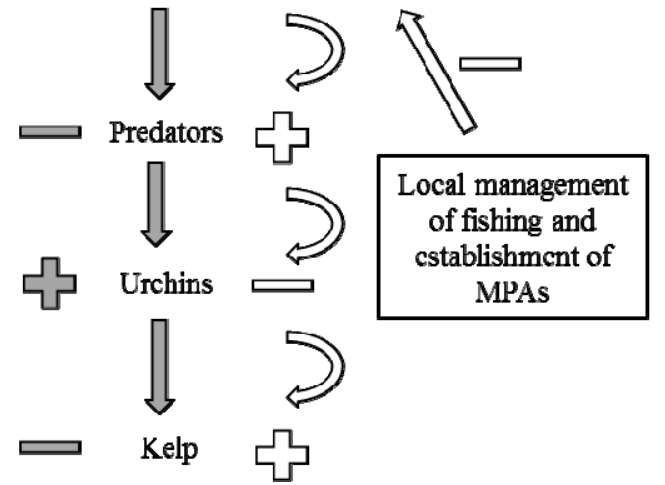

Management actions need to consider local conditions and address the stressors most relevant to that particular system. For example, in bottom-up driven kelp forest systems, the most efficient action would be to improve water quality reducing the competitive advantage of turfs over kelp. In a top-down driven kelp forest system, the best gain would be obtained by ensuring the presence of top predators and maintaining trophic cascades. As local stressors are ubiquitous, both systems would benefit from a more comprehensive management of stressors addressing the water quality issue and the persistence of trophic cascades, at the same time.

\section{Discussion-Acting on Rapidly Changing Local Stressors to Reduce the Effect of Global Stressors}

Human activities are sources and drivers of a number of stressors that cause environmental change. Local sources of pollution and habitat degradation (i.e., sediment runoff, eutrophication, overfishing, habitat destruction) have been known for many years and the key environmental consequences of those stressors are well understood. In recent decades, however, there has been an increasing number of cases where the ecological responses to stressors were different to what would be predicted [46]. To account for these ecological surprises it has been proposed that local stressors combine with global climate change stressors, such as ocean acidification and warming as synergies or antagonisms [47]. It can be anticipated that, as the number of stressors increases, the probability of synergistic interactions among them also increases. What is difficult to anticipate is how their various interactions propagate through a web of direct and indirect effects of species interactions, but recognizing known context-dependencies within these systems provides a useful starting point [20].

We have focused on synergistic effects (i.e., a positive feedback that is multiplicative), but we also highlight the need to investigate interactions between global and local stressors as antagonistic effects (i.e., negative feedback that is multiplicative). The results of such ecological research should not only lead to investigation of the possibility of disrupting synergies (positive feedbacks), but also facilitating antagonisms (negative feedbacks) [14]. While environmental forcing is often predicted to create 
profound community reorganization, it may result in relatively small net change in community structure (i.e., function 'stability' as opposed to 'resilience'). Compensatory processes occur within community dynamics to create strong stabilizing effects at the community level [48]. Compensatory effects are critical to the long-term sustainability of ecosystems in the face of environmental changes. This stabilizing effect of compensatory processes is of considerable interest because it suggests that ecological systems have some long-term capacity for sustainability as environments change. Where compensatory effects buffer ecosystems against environmental variations, losses of compensatory processes will not only impair ecosystem persistence, but it will also make ecosystem-shifts more variable and less predictable.

Response to climate change not only requires changes to global policies, but also changes to regional management of local stressors. At local scales, the stability and resilience of natural systems may be improved by activities that reduce the loss of predators (e.g., regulating fishing, planning MPAs), reduce habitat degradation (e.g., reducing water pollution) and restore degraded habitats [49]. We discussed how this local response may reduce unwanted ecological change, particularly where local and global stressors combine in synergistic ways to accelerate change. It is likely that most systems do not abruptly shift from one state to another, but shift gradually over multiple generations [50]. The effort, however, needed to reverse a regime shift, once it is started, can be much greater than that needed to cause the transition [42]. Effective management of local stressors has the capacity to substantially reduce the synergistic effects of multiple stressors and slow down the pace of environmental change.

Managers are only now starting to recognize the occurrence of synergistic effects, thus also recognizing the need for policy to act simultaneously across a number of stressors, rather than on single stressors individually. The ability of governments to manage stressors, has improved over the years, such that the governance of pollution, fishing, marine protected areas are more often administered through a collaborative effort by multiple departments. As research into the effects of global climate change stressors improves our understanding of synergies between global and local stressors and the capacity for local governments to manage them, communication and coordination between departments will only be improved. In this regard, an even more unified response to managing the natural environment would only improve our ability to increase the resilience of natural systems to global and local stressors.

\section{Acknowledgments}

Research funding was provided by an ARC grant to S.D.C. and B.D.R. Support was provided by an IPRS Scholarship (University of Adelaide) to G.G and an ARC Future Fellowship to S.D.C.

\section{Conflicts of Interest}

Authors declare no conflict of interest.

\section{References}

1. IPCC (Intergovernmental Panel on Climate Change). The Physical Science Basis; Contribution of Working Group I to the Fourth Assessment Report of the Intergovernmental Panel on Climate Change; Cambridge University Press: Cambridge, UK, 2007. 
2. IPCC. Managing the Risks of Extreme Events and Disasters to Advance Climate Change Adaptation; A Special Report of Working Groups I and II of the Intergovernmental Panel on Climate Change; Cambridge University Press: Cambridge, UK, 2012.

3. Harley, C.G.; Connell, S. Shifts in abiotic variables and consequences for diversity. In Marine Hard Bottom Communities; Wahl, M., Ed.; Springer: Berlin, Germany, 2009; pp. 257-268.

4. Godbold, J.A.; Solan, M. Long-term effects of warming and ocean acidification are modified by seasonal variation in species responses and environmental conditions. Philos. Trans. R. Soc. B Biol. Sci. 2013, 368, doi: 10.1098/rstb.2013.0186.

5. Hönisch, B.; Ridgwell, A.; Schmidt, D.N.; Thomas, E.; Gibbs, S.J.; Sluijs, A.; Zeebe, R.; Kump, L.; Martindale, R.C.; Greene, S.E.; et al. The Geological record of ocean acidification. Science 2012, 335, 1058-1063.

6. Joshi, M.; Hawkins, E.; Sutton, R.; Lowe, J.; Frame, D. Projections of when temperature change will exceed $2{ }^{\circ} \mathrm{C}$ above pre-industrial levels. Nat. Clim. Change 2011, 1, 407-412.

7. Caldeira, K.; Wickett, M.E. Anthropogenic carbon and ocean pH. Nature 2003, 425, 365.

8. Raven, J.R.; Caldeira, K.; Elderfield, H.; Hoegh-Guldberg, O.; Liss, P.; Riebesell, U.; Shepherd, J.; Turley, C.; Watson, A.; Heap, R.; et al. Ocean Acidification Due to Increasing Atmospheric Carbon Dioxide; The Royal Society: London, UK, 2005.

9. Doney, S.C.; Schimel, D.S. Carbon and climate system coupling on timescales from the precambrian to the anthropocene. Annu. Rev. Environ. Resour. 2007, 32, 31-66.

10. Piazzi, L.; Balata, D.; Ceccherelli, G.; Cinelli, F. Interactive effect of sedimentation and Caulerpa racemosa var. cylindracea invasion on macroalgal assemblages in the Mediterranean Sea. Estuar. Coast. Shelf Sci. 2005, 64, 467-474.

11. Worm, B.; Lotze, H.K. Effects of eutrophication, grazing, and algal blooms on rocky shores. Limnol. Oceanogr. 2006, 51, 569-579.

12. Jackson, J.B.C.; Kirby, M.X.; Berger, W.H.; Bjorndal, K.A.; Botsford, L.W.; Bourque, B.J.; Bradbury, R.H.; Cooke, R.; Erlandson, J.; Estes, J.A.; et al. Historical overfishing and the recent collapse of coastal ecosystems. Science 2001, 293, 629-637.

13. Bulleri, F.; Chapman, M.G. The introduction of coastal infrastructure as a driver of change in marine environments. J. Appl. Ecol. 2010, 47, 26-35.

14. Brown, C.J.; Saunders, M.I.; Possingham, H.P.; Richardson, A.J. Managing for interactions between local and global stressors of ecosystems. PLOS ONE 2013, 8, e65765.

15. Wilson, S.K.; Graham, N.A.J.; Pratchett, M.S.; Jones, G.P.; Polunin, N.C.V. Multiple disturbances and the global degradation of coral reefs: Are reef fishes at risk or resilient? Glob. Change Biol. 2006, 12, 2220-2234.

16. Hall, J.; Gruber, N.; Díaz, R.; Wilhelmsson, D. The impacts of multiple stressors: A complex web of challenges. In Valuing the Ocean; Noone, K., Sumaila, R., Díaz, R.J., Eds.; Stockholm Environment Institute: Stockholm, Sweden, 2013.

17. Crain, C.M.; Kroeker, K.; Halpern, B.S. Interactive and cumulative effects of multiple human stressors in marine systems. Ecol. Lett. 2008, 11, 1304-1315.

18. Anthony, K.R.N.; Maynard, J.A.; Diaz-Pulido, G.; Mumby, P.J.; Marshall, P.A.; Cao, L.; Hoegh-Guldberg, O. Ocean acidification and warming will lower coral reef resilience. Glob. Change Biol. 2011, 17, 1798-1808. 
19. Connell, S.D.; Russell, B.D. The direct effects of increasing $\mathrm{CO}_{2}$ and temperature on non-calcifying organisms: Increasing the potential for phase shifts in kelp forests. Proc. R. Soc. Biol. Sci. 2010, 277, 1409-1415.

20. Pettorelli, N. Climate change as a main driver of ecological research. J. Appl. Ecol. 2012, 49, 542-545.

21. Wooldridge, S.A. Water quality and coral bleaching thresholds: Formalising the linkage for the inshore reefs of the Great Barrier Reef, Australia. Mar. Pollut. Bull. 2009, 58, 745-751.

22. Connell, S.D.; Kroeker, K.J.; Fabricius, K.E.; Kline, D.I.; Russell, B.D. The other ocean acidification problem: $\mathrm{CO}_{2}$ as a resource among competitors for ecosystem dominance. Philos. Trans. R. Soc. B Biol. Sci. 2013, 20120442.

23. Bulling, M.T.; Hicks, N.; Murray, L.; Paterson, D.M.; Raffaelli, D.; White, P.C.L.; Solan, M. Marine biodiversity-ecosystem functions under uncertain environmental futures. Philos. Trans. R. Soc. B Biol. Sci. 2010, 365, 2107-2116.

24. Xu, Z.; Zou, D.; Gao, K. Effects of elevated $\mathrm{CO}_{2}$ and phosphorus supply on growth, photosynthesis and nutrient uptake in the marine macroalga Gracilaria lemaneiformis (Rhodophyta). Bot. Mar. 2010, 53, 123-129.

25. Hughes, T.P.; Rodrigues, M.J.; Bellwood, D.R.; Ceccarelli, D.; Hoegh-Guldberg, O.; McCook, L.; Moltschaniwskyj, N.; Pratchett, M.S.; Steneck, R.S.; Willis, B. Phase shifts, herbivory, and the resilience of coral reefs to climate change. Curr. Biol. 2007, 17, 360-365.

26. Gorman, D.; Connell, S.D. Recovering subtidal forests in human-dominated landscapes. J. Appl. Ecol. 2009, 46, 1258-1265.

27. Waycott, M.; Duarte, C.M.; Carruthers, T.J.B.; Orth, R.J.; Dennison, W.C.; Olyarnik, S.; Calladine, A.; Fourqurean, J.W.; Heck, K.L., Jr.; Hughes, A.R.; et al. Accelerating loss of seagrasses across the globe threatens coastal ecosystems. Proc. Natl. Acad. Sci. USA 2009, 106, 12377-12381.

28. Dayton, P.K. Ecology of kelp communities. Annu. Rev. Ecol. Syst. 1985, 16, 215-245.

29. Goodsell, P.J.; Fowler-Walker, M.J.; Gillanders, B.M.; Connell, S.D. Variations in the configuration of algae in subtidal forests: Implications for invertebrate assemblages. Austral Ecol. 2004, 29, 350-357.

30. Smale, D.A.; Wernberg, T. Extreme climatic event drives range contraction of a habitat-forming species. Proc. R. Soc. B Biol. Sci. 2013, 280, doi: 10.1098/rspb.2012.2829.

31. Dayton, P.K.; Tegner, M.J. Catastrophic storms, El-Nino, and patch stability in a southern California kelp community. Science 1984, 224, 283-285.

32. Graham, M.H. Effects of local deforestation on the diversity and structure of Southern California giant kelp forest food webs. Ecosystems 2004, 7, 341-357.

33. Steneck, R.S.; Graham, M.H.; Bourque, B.J.; Corbett, D.; Erlandson, J.M.; Estes, J.A.; Tegner, M.J. Kelp forest ecosystems: Biodiversity, stability, resilience and future. Environ. Conserv. 2002, 29 , 436-459.

34. Kennelly, S.J. Inhibition of kelp-recruitment by turfing-algae and consequences for an Australasian kelp-community. J. Exp. Mar. Biol. Ecol. 1987, 112, 49-60.

35. Connell, S.D. The monopolization of understorey habitat by subtidal encrusting coralline algae: A test of the combined effects of canopy-mediated light and sedimentation. Mar. Biol. 2003, 142, 1065-1071. 
36. Irving, A.D.; Connell, S.D. Physical disturbance by kelp abrades erect algae from the understorey. Mar Ecol. Prog. Ser. 2006, 324, 127-137.

37. Airoldi, L. The effects of sedimentation on rocky coast assemblages. Oceanogr. Mar. Biol. 2003, 41, 161-236.

38. Connell, S.D.; Russell, B.D.; Turner, D.J.; Shepherd, S.A.; Kildea, T.; Miller, D.; Airoldi, L.; Cheshire, A. Recovering a lost baseline: Missing kelp forests from a metropolitan coast. Mar. Ecol. Prog. Ser. 2008, 360, 63-72.

39. Falkenberg, L.J.; Russell, B.D.; Connell, S.D. Contrasting resource limitations of marine primary producers: Implications for competitive interactions under enriched $\mathrm{CO}_{2}$ and nutrient regimes. Oecologia 2013, 172, 575-583.

40. Hepburn, C.D.; Pritchard, D.W.; Cornwall, C.E.; McLeod, R.J.; Beardall, J.; Raven, J.A.; Hurd, C.L. Diversity of carbon use strategies in a kelp forest community: Implications for a high $\mathrm{CO}_{2}$ ocean. Glob. Change Biol. 2011, 17, 2488-2497.

41. Russell, B.D.; Thompson, J.-A.I.; Falkenberg, L.J.; Connell, S.D. Synergistic effects of climate change and local stressors: $\mathrm{CO}_{2}$ and nutrient-driven change in subtidal rocky habitats. Glob. Change Biol. 2009, 15, 2153-2162.

42. Falkenberg, L.J.; Connell, S.D.; Russell, B.D. Disrupting the effects of synergies between stressors: Improved water quality dampens the effects of future $\mathrm{CO}_{2}$ on a marine habitat. J. Appl. Ecol. 2013, 50, 51-58.

43. Ling, S.D.; Johnson, C.R.; Frusher, S.D.; Ridgway, K.R. Overfishing reduces resilience of kelp beds to climate-driven catastrophic phase shift. Proc. Natl. Acad. Sci. USA 2009, 106, 22341-22345.

44. Ling, S.D.; Johnson, C.R. Marine reserves reduce risk of climate-driven phase shift by reinstating size- and habitat-specific trophic interactions. Ecol. Appl. 2012, 22, 1232-1245.

45. Foster, M.S.; Schiel, D.R. Loss of predators and the collapse of southern California kelp forests (?): Alternatives, explanations and generalizations. J. Exp. Mar. Biol. Ecol. 2010, 393, 59-70.

46. Russell, B.D.; Connell, S.D. Origins and consequences of global and local stressors: Incorporating climatic and non-climatic phenomena that buffer or accelerate ecological change. Mar. Biol. 2012, 159, 2633-2639.

47. Boyd, P.W.; Hutchins, D.A. Understanding the responses of ocean biota to a complex matrix of cumulative anthropogenic change. Mar. Ecol. Prog. Ser. 2012, 470, 125-135.

48. Gonzalez, A.; Loreau, M. The causes and consequences of compensatory dynamics in ecological communities. Annu. Rev. Ecol. Evol. Syst. 2009, 40, 393-414.

49. Ruckelshaus, M.; Doney, S.C.; Galindo, H.M.; Barry, J.P.; Chan, F.; Duffy, J.E.; English, C.A.; Gaines, S.D.; Grebmeier, J.M.; Hollowed, A.B.; et al. Securing ocean benefits for society in the face of climate change. Mar. Policy 2013, 40, 154-159.

50. Hughes, T.P.; Linares, C.; Dakos, V.; van de Leemput, I.A.; van Nes, E.H. Living dangerously on borrowed time during slow, unrecognized regime shifts. Trends Ecol. Evol. 2013, 28, 149-155.

(C) 2013 by the authors; licensee MDPI, Basel, Switzerland. This article is an open access article distributed under the terms and conditions of the Creative Commons Attribution license (http://creativecommons.org/licenses/by/3.0/). 